\title{
A tuberculin skin test survey among Ghanaian school children
}

\author{
Kennedy Kwasi Addo ${ }^{1 *}$, Susan van den Hof ${ }^{3,4}$, Gloria Ivy Mensah", Adukwei Hesse ${ }^{5}$, Christian Bonsu', \\ Kwadwo Ansah Koram², Felix Kwami Afutu', Frank Adae Bonsu ${ }^{6}$
}

\begin{abstract}
Background: Ghana has not conducted a national tuberculin survey or tuberculosis prevalence survey since the establishment of the National Tuberculosis Control Programme. The primary objective of this study was therefore to determine the prevalence of tuberculin skin sensitivity in Ghanaian school children aged 6-10 years in 8 out of 10 regions of Ghana between 2004 and 2006.
\end{abstract}

Methods: Tuberculin survey was conducted in 179 primary schools from 21 districts in 8 regions. Schools were purposively selected so as to reflect the proportion of affluent private and free tuition public schools as well as the proportion of small and large schools.

Results: Of the 24,778 children registered for the survey, 23,600 (95.2\%) were tested of which 21,861 (92.6\%) were available for reading. The age distribution showed an increase in numbers of children towards older age: $11 \%$ of the children were 6 years and 25\%, 10 years. Females were $52.5 \%$ and males $47.5 \%$. The proportion of girls was higher in all age groups (range $51.4 \%$ to $54.0 \%, p<0.001$ ). BCG scar was visible in $89.3 \%$ of the children. The percentage of children with a BCG scar differed by district and by age. The percentage of children with a BCG scar decreased with increasing age in all districts, reflecting increasing BCG vaccination coverage in Ghana in the last ten years. The risk of tuberculosis infection was low in the northern savannah zones compared to the southern coastal zones. Using a cut-off of $15 \mathrm{~mm}$, the prevalence of infection ranged from $0.0 \%$ to $5.4 \%$ and the Annual Risks of Tuberculosis Infection $0.0 \%$ to $0.6 \%$. There was an increase in the proportion of infected children after the age of 7 years. Children attending low and middle-class schools had a higher risk of infection than children attending upper-class schools.

Conclusion: Tuberculosis infection is still a public health problem in Ghana and to monitor the trend, the survey needs to be repeated at 5 years interval.

\section{Background}

Ghana is a West African country, bordering Burkina Faso to the north, Togo to the east, Cote d'Ivoire to the west and the Gulf of Guinea to the south. For administrative purposes, the country is divided into 10 regions and subdivided into 168 districts. Topographically, Ghana is divided into three ecological zones. The southern regions (Western, Central, Volta, Greater-Accra) make up the coastal zone, the central regions (Brong Ahafo, Ashanti, Eastern) the forest zone, and the northern regions (Upper-East, Upper-West, Northern) the

\footnotetext{
* Correspondence: kaddo@noguchi.mimcom.org

'Bacteriology Department, Noguchi Memorial Institute for Medical Research,
} Legon, Ghana

C 2010 Addo et al; licensee BioMed Central Ltd. This is an Open Access article distributed under the terms of the Creative Commons Attribution License (http://creativecommons.org/licenses/by/2.0), which permits unrestricted use, distribution, and reproduction in any medium, provided the original work is properly cited. savannah zone. Of the 22.5 million population of Ghana, $34 \%$ live in the southern coast, $48 \%$ in the central forest, and $18 \%$ in the northern savannah areas [1]. With estimated 46,693 new cases of all forms of tuberculosis (TB) in 2006, Ghana has the $15^{\text {th }}$ highest burden in Africa [2].

The National Tuberculosis Control Programme (NTP) was established in 1994 to attempt among others to reduce the incidence and prevalence of TB in the country and the Directly Observed Therapy Shortcourse (DOTS) strategy was introduced the same year. DOTS coverage reached $100 \%$ in 2005 and 12,124 TB cases of which 7,505 were new smear positive were notified for an incidence rate of 55 and 34 per 100,000 respectively [2]. 
Using tuberculin survey to assess the extent of TB infection in Ghana has never been done since the establishment of the NTP. In 1957, a World Health Organization (WHO) sponsored study reported a point TB prevalence of $0.2 \%$ to $0.9 \%$ in the general population and $0.4 \%$ to $3 \%$ in the gold mining areas [3]. Surveys done in the late seventies in some urban areas estimated the prevalence of infection to be between $1 \%$ and $2 \%$ $[4,5]$.

These data are old and as disease reporting is also inadequate, there was an urgent need to establish recent risk of infection in Ghana and provide baseline data for the NTP.

This baseline tuberculin survey was therefore carried out to establish the recent risk of TB infection in different parts of Ghana. It was conducted in 2004 - 2006 among primary school children in eight regional capitals and their environs where Public-Private Mix (PPM) activities in TB control were to be implemented in response to a rapidly growing private health sector in the country, especially in cities. PPM activities aim to involve all health care providers - public and private as well as formal and informal in the provision of TB diagnosis and treatment according to international guidelines. The study population comprised school children because the annual risk of tuberculosis infection (ARTI) which is a measure for transmission of TB infection in the population is better calculated from the prevalence of infection estimated throughcross-sectional tuberculin surveys. ARTI estimates obtained from children reflect on relatively recent disease situation and its trends. In older age groups, higher prevalence of environmental mycobacteria and HIV infection may interfere with the interpretation of the survey results.

\section{Methods}

\section{Study population}

The study population comprised primary school children aged between 6 and 10 years from 21 districts in 8 out of 10 regions of Ghana namely; Greater-Accra, Ashanti, Eastern, Central, Western, Northern, Upper East and Upper West.

\section{Sampling}

A list of all primary schools in the eight regions was obtained from the Ghana Education Service. Schools in the regional capitals and its bordering districts were selected purposively to reflect the proportion of affluent private and free tuition public schools and small and large schools.

\section{Training}

Testers, readers and the other members of the tuberculin team received two weeks training in testing, reading, scar examination and other logistics of performing a tuberculin survey following international guidelines by
Royal Netherlands Tuberculosis Foundation (KNCV) reference nurse before the start of the survey. The training was combined with a pilot survey.

\section{Tuberculin test}

A dose of tuberculin of $2 \mathrm{TU}$ in $0.1 \mathrm{ml}$ PPD RT23/ Tween 80 from State Serum Institute (SSI) Copenhagen, batch number 1449A was used. Bacille Calmette-Guérin (BCG) vaccination status of each school child to be tested was assessed by physical examination for the presence or absence of a BCG scar. A dose of exactly 0.1 $\mathrm{ml}$ was slowly injected (intradermally-Mantoux technique) $[6,7]$. In case of injury or scar on the left forearm, the test was given on right forearm and a note made in the comments column of the data form. The reaction to the test was read 72 hours after administration. If an induration was present its limits were determined and its largest transverse diameter measured in millimeters with a transparent flexible ruler of $15 \mathrm{~cm}[7,8]$. Each induration was assessed by one reader but when in doubt a reference reader was called to read.

\section{Data management}

The team leader verified completeness of the raw data on-site after each days' activity before being double entered into a data entry file - Microsoft Office Excel 2003 (Microsoft Excel, Palisade Corp, Newfield, NY, USA). Afterwards, the data files were compared to the raw data by one of the authors. Missing values, inconsistencies and outlier values were checked and corrected where necessary. Analysis of the data was done with SPSS version 15 (SPSS, Inc, Chicago, IL, USA).

\section{Data analysis}

Schools were classified as being situated in urban, periurban or rural areas and as upper, middle, or lower class. Age was reported as age in full years since the last birthday. Mean and median ages were calculated by adding 0.5 years to the reported age because on average the children are expected to be 6 months older than the age in full years. Differences in proportions were tested for statistical significance by the chi-square test.

We assessed whether there was a difference in the results in children with and without BCG scar. We also assessed whether terminal digit preference (tendency to round observations to numbers ending with zero or 5) was present by smoothing the data. This involves calculating the expected frequency at each millimeter $(\mathrm{mm})$ of reaction as the average of three or five frequencies including one or two before and after the induration of interest [9].

Specific cut off levels ( $\geq 10 \mathrm{~mm}$ and $\geq 15 \mathrm{~mm}$ ) were used to distinguish between infected and un-infected children. The mirror method which is based on the observation that the distribution of tuberculin reactions reflects two underlying distributions: that of reactions to TB infection and that of non-specific reactions was also 
used [10-12]. It assumes that the tuberculin reactions among infected children are normally distributed around a mode of 16 to $17 \mathrm{~mm}$ and that there are no non-specific reactions larger than the mode. Indurations equal to the mode are counted once and all larger than the mode counted twice to obtain the estimated number of indurations. In our analyses we assumed the mode to be at 16 and $17 \mathrm{~mm}$, as these values are used often in literature [12,13].

Data was analysed per district to obtain estimates of TB infection and ARTI. The ARTI was calculated as 1 (1-prevalence of infection $)^{1 / \text { mean age }}$ [14].

The estimated ARTI is the average of the annual risks of infection experienced by the study sample from birth to the time of survey [15]. This risk may not have been constant over the period. Therefore, we assumed that the estimated ARTI corresponds closely to the midpoint of the average life of the individuals included in the survey.

\section{Management of positive reactors}

The NTP guidelines state that BCG vaccinated children with a Tuberculin Skin Test (TST) $\geq 15 \mathrm{~mm}$ and unvaccinated children with a TST $\geq 10 \mathrm{~mm}$ who are household contacts of a TB case and have symptoms of TB should be treated with anti-TB drugs. Children with TST $\geq 15$ or $10 \mathrm{~mm}$ respectively, without a household contact but with symptoms of TB will be investigated further and treated for TB disease if necessary. During the survey, children with TST result of $\geq 15 \mathrm{~mm}$ for vaccinated and $\geq 10 \mathrm{~mm}$ for unvaccinated were therefore regarded as potentially infected and were referred to the local health facilities for further investigations.

\section{Ethical considerations}

The study was approved by the Scientific and Technical Committee and the Institutional Review Board, FederalWide Assurance 00001824 of the Noguchi Memorial Institute for Medical Research, Legon, Ghana in 2003 (reference number NMIMR-IRB CPN 022/02-03). Parents were requested to sign a written informed consent form. Only children that brought the signed informed consent form were included in the survey. Permission to enter the selected schools was sought from the Ministry of Education.

\section{Results}

\section{Study population}

The study covered children from 179 primary schools selected from a total of 338 schools in 21 districts in 8 out of 10 regions of Ghana. Children aged 6-10 years with consent form were 24,778. However, 23,600 (95.2\%) were available for testing for which 21,861 (92.6\%) were read (Table 1). The total number of eligible pupils per school was not registered, so the participation rate could not be calculated. However, from the experience of the field team, participation was nearly $100 \%$ in most public schools and much lower in some of the upper-class schools. The percentage of children whose tests were read varied from $74.1 \%$ to $99.2 \%$. In districts with reading percentages below $90 \%$, a national holiday, sports event, and rainy day were reasons for the low readings.

\section{Age and sex distribution}

The age distribution showed an increase in numbers of children towards older age: $11 \%$ were 6 years and 25\%, 10 years. The proportion of girls was higher in all age groups (range $51.4 \%$ to $54.0 \%, \mathrm{p}<0.001$ ).

\section{BCG scar}

BCG scar was visible in $89.3 \%$ of the children. It decreased with increasing age in all districts, the crude average increased from $87.1 \%$ in 10 -year-olds to $92.5 \%$ in 6-year-olds, reflecting increasing BCG vaccination coverage in Ghana in the last ten years. The distribution of schoolchildren with BCG scar by age was similar in boys and girls, both in the total population $(\mathrm{p}=0.31)$ and on the district level. The percentage of schoolchildren with BCG scar was highest in schools in urban areas (94.4\%) and upper-class schools (92.2\%).

\section{TST reaction}

No reaction was observed in $41.9 \%$ of those with and $49.1 \%$ of those without BCG scar $(\mathrm{p}<0.01)$. The percentage of non-reactors was highest in the districts in the Ashanti region and lowest in the districts sampled from the Eastern and Central regions.

The distribution of reaction sizes is shown in Figure 1. As expected, the size of reaction was less than $5 \mathrm{~mm}$ in most children. However, the proportion of children with reaction less than $5 \mathrm{~mm}$ was less in those from Ashanti and Greater Accra regions which were surveyed first compared to the other six regions.

The frequency distribution of reaction sizes $>0 \mathrm{~mm}$ by BCG scar status is shown in Figure 2. There was no relevant effect of the presence of a BCG scar on tuberculin reaction size. The reaction sizes of all children were therefore used to estimate the prevalence of TB infection and the ARTI.

ARTI

The frequency distribution of the reaction sizes showed digit preference at 10 and $15 \mathrm{~mm}$. Using 5 point moving average seemed to provide the best correction of digit preference. Estimating the prevalence of infection using smoothed data did not show significant differences from the estimates based on the original data hence, the latter was used for the analysis.

The frequency distribution of the reaction sizes did not show a bimodal distribution. Therefore, it was not clear which method and cut-off point would provide the best estimate of the prevalence of TB infection and ARTI. In view of this, we resorted to the often used cutoff points of 16 and $17 \mathrm{~mm}$. 
Table 1 Region, district, number of schools and children tested and read

\begin{tabular}{|c|c|c|c|c|c|c|c|c|}
\hline Region & District & $\begin{array}{l}\text { Total no of } \\
\text { schools }\end{array}$ & $\begin{array}{l}\text { No of schools } \\
\text { selected }\end{array}$ & $\begin{array}{l}\text { Children with informed } \\
\text { consent }\end{array}$ & $\begin{array}{l}\text { Children } \\
\text { tested }\end{array}$ & $\begin{array}{l}\% \\
\text { tested }\end{array}$ & $\begin{array}{l}\text { Children } \\
\text { read }\end{array}$ & $\begin{array}{l}\% \\
\text { read }\end{array}$ \\
\hline Eastern & New Juaben & 40 & 28 & 3333 & 3279 & 98.4 & 3051 & 93.0 \\
\hline \multirow[t]{3}{*}{ Central } & AAK & 5 & 2 & 496 & 457 & 92.1 & 387 & 84.7 \\
\hline & Cape Coast & 40 & 22 & 3125 & 3036 & 97.2 & 2815 & 92.7 \\
\hline & KEEA & 7 & 4 & 653 & 636 & 97.4 & 621 & 97.6 \\
\hline \multirow[t]{3}{*}{ Northern } & $\begin{array}{l}\text { Savlegu- } \\
\text { Nanton }\end{array}$ & 7 & 4 & 699 & 643 & 92.0 & 625 & 97.2 \\
\hline & Tamale & 25 & 14 & 2285 & 2085 & 91.2 & 1973 & 94.6 \\
\hline & $\mathrm{T}-\mathrm{K}$ & 15 & 7 & 756 & 705 & 93.3 & 673 & 95.5 \\
\hline \multirow[t]{3}{*}{ Western } & Ahanta-East & 35 & 18 & 3005 & 2822 & 93.9 & 2699 & 95.6 \\
\hline & Ahanta-West & 5 & 3 & 808 & 777 & 96.2 & 576 & 74. 1 \\
\hline & Wassa-West & 10 & 6 & 1033 & 987 & 95.5 & 889 & 90.0 \\
\hline Upper-East & Bolga & 15 & 7 & 840 & 799 & 95.1 & 765 & 95.7 \\
\hline Upper-West & Wa & 7 & 4 & 647 & 638 & 98.6 & 622 & 97.5 \\
\hline \multirow[t]{4}{*}{ Ashanti } & AN & 8 & 4 & 255 & 250 & 98. 0 & 240 & 96.0 \\
\hline & BAK & 6 & 3 & 389 & 385 & 99.0 & 382 & 99.2 \\
\hline & Ejisu-Juaben & 5 & 2 & 139 & 137 & 98.6 & 133 & 97.0 \\
\hline & Kumasi & 55 & 27 & 2815 & 2678 & 95.1 & 2407 & 89. 9 \\
\hline \multirow{5}{*}{$\begin{array}{l}\text { Greater- } \\
\text { Accra }\end{array}$} & Accra & 15 & 6 & 990 & 959 & 96.9 & 895 & 93.3 \\
\hline & Dangme-East & 7 & 3 & 197 & 179 & 90.9 & 169 & 94.4 \\
\hline & $\begin{array}{l}\text { Dangme- } \\
\text { West }\end{array}$ & 10 & 5 & 586 & 538 & 91.8 & 472 & 87.7 \\
\hline & $\mathrm{Ga}$ & 15 & 7 & 1012 & 933 & 92.2 & 848 & 90.9 \\
\hline & Tema & 6 & 3 & 715 & 677 & 94.7 & 619 & 91.4 \\
\hline Total & & 338 & 179 & 24,778 & 23,600 & 95.2 & 21,861 & 92.6 \\
\hline
\end{tabular}

AAK = Abura Asebu Kowmanse, KEEA = Komenda Edina Eguafo Abirem, T-K = Tolon-Kumbungu

AN = Atwima Nwobeagya, BAK = Bosumtwi Atwima Kwabianya

Additional file 1, Tables S2 and S3 show the prevalence of infection and ARTI in the districts calculated using different methods. Using cut-off of $10 \mathrm{~mm}$ produced estimates for the prevalence of infection and ARTI which were different from those obtained using cut-off of $15 \mathrm{~mm}$ and the mirror method at 16 or 17 $\mathrm{mm}$. If we assume that a cut of $10 \mathrm{~mm}$ overestimates the prevalence of infection and ARTI (3.3\% to $18.8 \%$ and $0.4 \%$ to $2.4 \%$ respectively), we can assume that the other methods will probably reflect the range in which the best estimate of the prevalence of infection and ARTI will lie within the districts. Using a cut-off of 15 $\mathrm{mm}$ the prevalence of infection ranged from $0.0 \%$ to $5.4 \%$ and ARTI from $0.0 \%$ to $0.6 \%$ respectively. The risk of TB infection was lowest in the districts sampled from northern savannah and highest in districts sampled from southern coastal zone.

Figure 3 shows a consistent increase in the prevalence of infection with age after the age of seven years, regardless of which method was used. This did not change when the data was stratified with the presence or absence of BCG scar (data not shown).

Figure 4 shows a positive correlation between the estimated prevalence of infection and ARTI and the notification rates from each region.

\section{Discussion}

Tuberculin surveys have some general limitations: a) schools are usually the point of entry and children not at school are likely to have a higher risk of TB because 


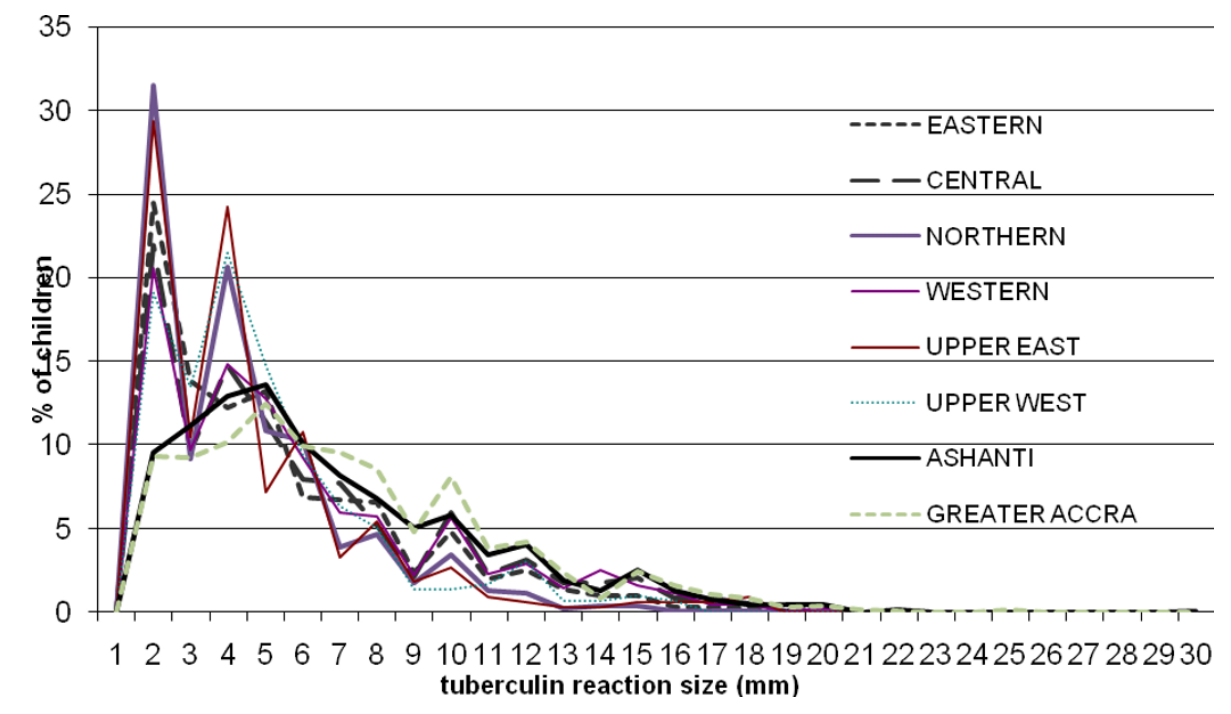

Figure 1 Distribution of tuberculin reaction sizes by region, in children with reaction size $>0 \mathrm{~mm}$.

they tend to come from lower socio-economic classes [16]. Although there are no exact figures on school attendance in Ghana, it is assumed to be high. However, we observed a lower attendance in 6- and 7-yearolds compared to 8- to 10-year-olds and in rural compared to urban areas. Especially in these groups, the obtained estimates for risk of TB infection may be an underestimation; b) BCG scars are usually taken as proxy for BCG vaccination status. As children vaccinated at birth may not develop a scar, vaccination coverage was probably higher than the proportion of children with BCG scar observed in this survey (89.3\%).
Other limitations identified were related mostly to sampling in this survey. Firstly, the districts sampled were from the capital cities and surrounding districts of the eight regions where PPM activities were being implemented. Therefore, they are not fully representative of all districts in the regions. No regional or national estimates of the risk of infection can be deduced from these data, only district estimates. Secondly, schools were not sampled randomly within districts. However, they were selected with care to obtain representative selection of schools within the district so we assume that this will not have introduced considerable bias. Thirdly, the characteristics of children

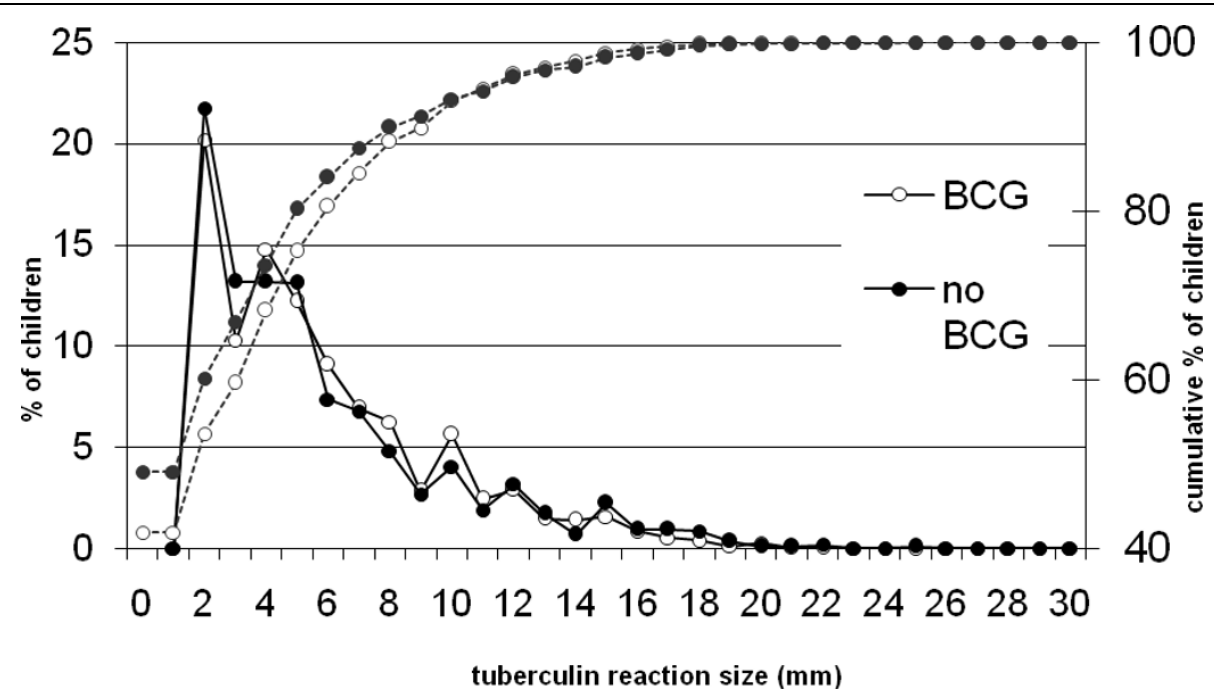

Figure 2 Distribution of the percentage of children with a reaction size $>0 \mathrm{~mm}$, and the cumulative percentage of children with a reaction size up to and including the size given on the $x$-axis, by BCG scar status. 


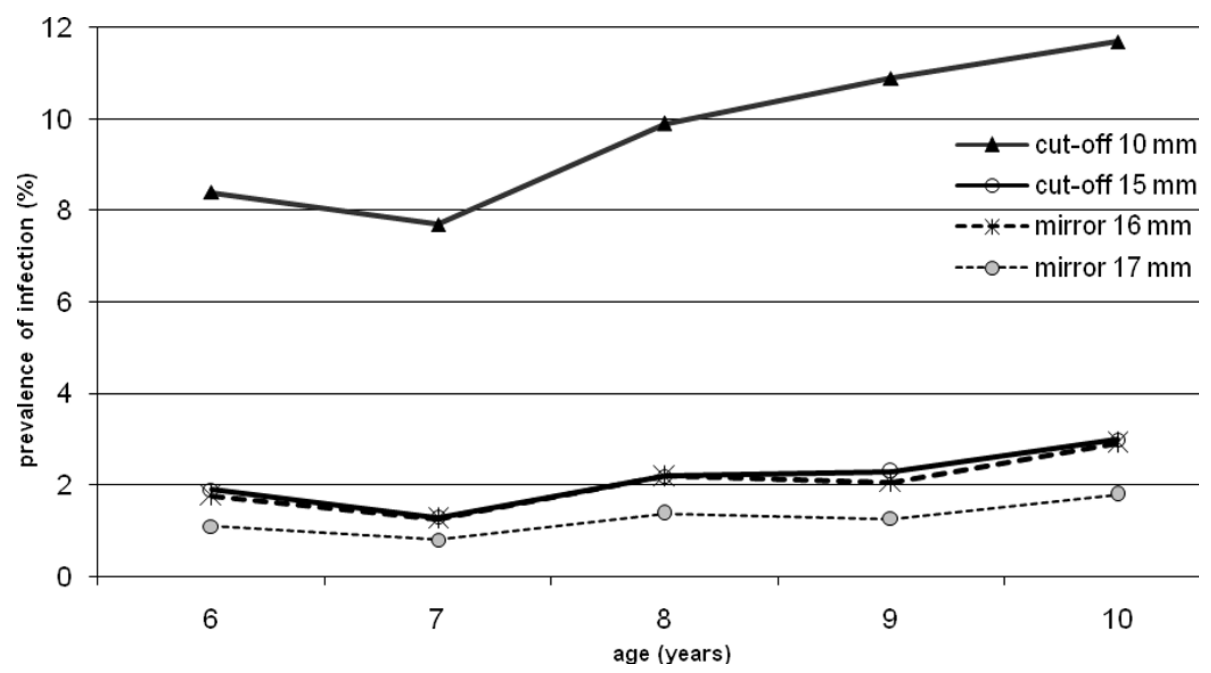

Figure 3 Prevalence of infection by age, as estimated by using different methods

who did not take part in the study because parental consent was not given was not determined. We therefore could not determine whether they were different from those studied. Fourthly, the number of children included in some districts was relatively small, making estimates for the risk of infection imprecise. Lastly, no bimodal distribution of reaction sizes was visible. Therefore, it was not possible to distinguish infected children from uninfected children and we estimated the prevalence of infection and ARTI by different methods to obtain a plausible range for these estimates. In this study, as also found in Tanzania [17], applying cut-off of $10 \mathrm{~mm}$ overestimated the ARTI. This may be due to limited specificity with this cut-off as a result of high prevalence of infections with nontuberculous mycobacteria (NTM) [17-19]. Despite its

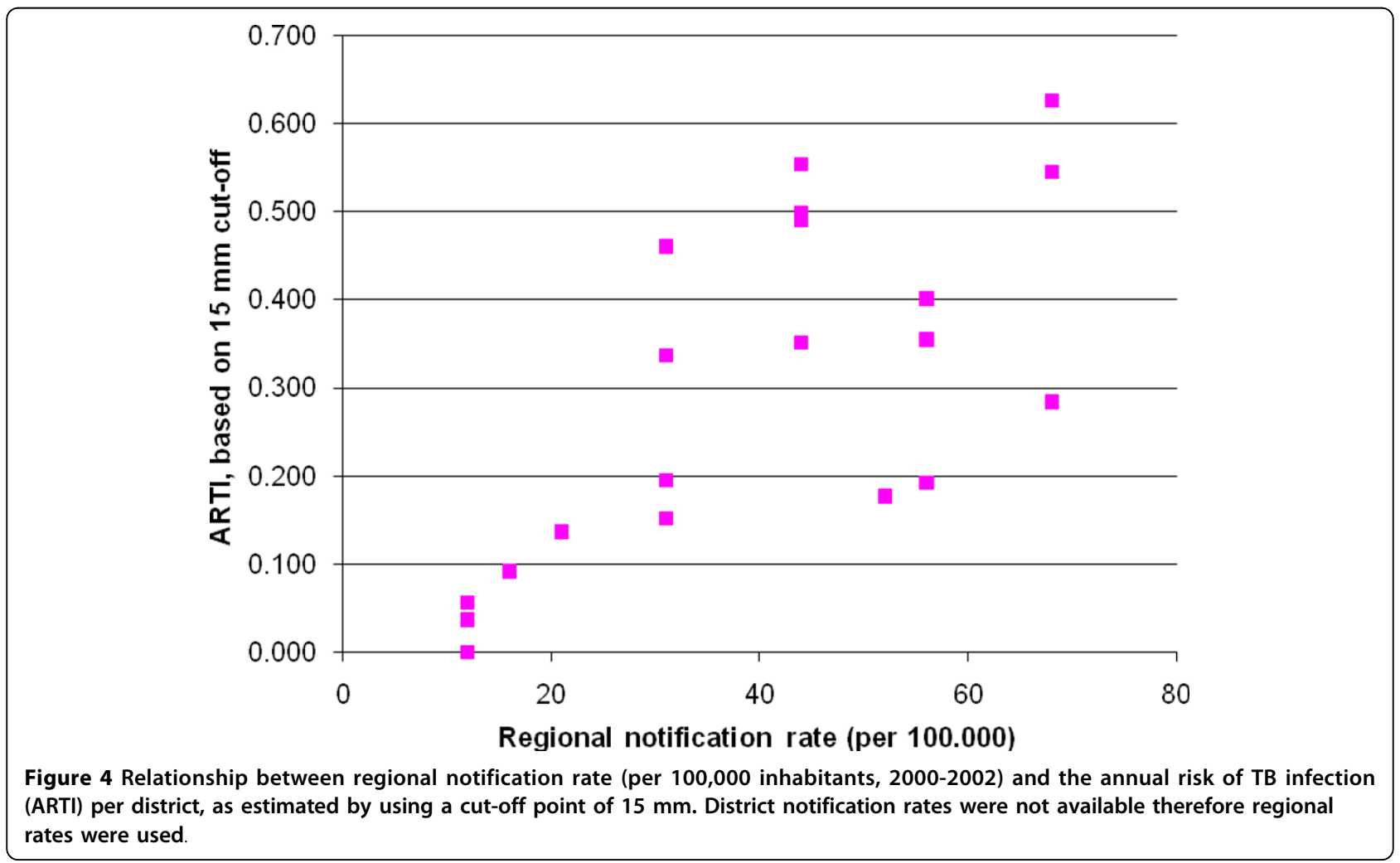


limitations, many useful results have become available through this survey. The risk of infection was lowest in the sparsely populated northern savannah and highest in the more populous southern coastal zones of the country an indication that control activities would have to focus more on the latter. There was a clear increase in the proportion of infected children by age after 7 years. Children attending low and middle-class schools had a higher risk of infection than children attending upper-class schools (data not shown). This is consistent with the theory that socio-economic status is an important determinant for TB infection and disease [16]. Unfortunately, it is not possible to extrapolate ARTI to TB incidence as the Styblo rule which states that "an annual incidence of 50 sputum-smear positive TB cases in a population of 100,000 generates ARTI of 1\%" is not applicable in DOTS settings [20]. However, there was a clear correlation between estimated prevalence of infection and ARTI on the one hand and the notification rates on the other. All districts in Greater Accra except Dangme-East had higher ARTI than expected based on notification rates. This may indicate that case detection rates are lower in the Greater Accra region than in most other districts sampled. In New Juaben, the only district selected in the Eastern region, a lower ARTI was observed than expected based on this association. However, as this concerns only one district, it is unclear whether this is a reflection of high case detection rates in this region. Wassa west is part of the mining region where high ARTI was observed in the 1950's [3]. However, in this survey, ARTI does not seem to be particularly high compared to other districts in the country.

Besides results on infection pattern, other interesting results emerged from the survey. The percentage of children with BCG scar decreased with age, reflecting an increased uptake of BCG in the last decennium. However, inequality in BCG coverage does exist as the percentage of children with BCG scar was highest in pupils visiting upper-class schools, and the overall proportion of children with BCG scar varied between districts (data not shown). These differences did not affect ARTI estimates as BCG vaccination had minimal effect on reaction sizes greater than $10 \mathrm{~mm}$, which are most relevant for determining the prevalence of infection [16].

We do not know why the distribution of non-reactors and reaction sizes varied between districts. A distribution with a higher proportion of lower reaction sizes is expected when cross-reaction to NTM are present. Unfortunately, data on national/regional prevalence of NTM in Ghana to relate to the distribution of reaction sizes is not available.

\section{Conclusion}

In conclusion, the survey has provided useful information to the NTP on TB transmission in Ghana and has helped to evaluate the programme performance. The positive correlation between the estimated prevalence of infection and ARTI and the notification rates from the regions had shown that the programme is performing well. From the results, it is highly recommended to repeat the survey at 5 years interval with particular attention on: 1) using the same districts and schools as in the current survey in order to assess trends in ARTI. 2) additional districts and schools would have to be randomly selected to make the selection representative of a region and to obtain sufficient numbers of children per region to narrow the confidence interval. 3) registering the total number of eligible children per school in order to calculate the participation rate, age group and gender, and 4) conducting tuberculin testing in a group of TB patients to assess their reaction sizes, which can be used to estimate the mode to be used in the mirror method for estimating the prevalence of infection.

\footnotetext{
Additional file 1: Tables S2 and S3. Table S2 - Prevalence of infection (with 95\% confidence intervals) per district as estimated by different methods. Table S3 - Annual risk of tuberculosis infection (ARTI) (with 95\% confidence intervals) per district as estimated by different methods. Click here for file

[http://www.biomedcentral.com/content/supplementary/1471-2458-1035-S1.DOC ]
}

\section{Acknowledgements}

The fieldwork for the tuberculin survey was supported by many individuals and organizations. We especially thank the Ministries of Education and Health for their support, the regional and district health and education officers, and the headmasters and teachers of the schools for assisting the field teams during testing and reading days. We are also grateful to the Global Fund Against HIV/AIDS, TB \& Malaria and the Ghana Health Service for their financial support.

\section{Author details}

'Bacteriology Department, Noguchi Memorial Institute for Medical Research, Legon, Ghana. 'Epidemiology Department, Noguchi Memorial Institute for Medical Research, Legon, Ghana. ${ }^{3}$ Research Unit, KNCV Tuberculosis Foundation, The Hague, The Netherlands. ${ }^{4}$ Center for Infection and Immunity Amsterdam (CINIMA), Academic Medical Center, University of Amsterdam, Amsterdam, The Netherlands. ${ }^{5}$ Department of Medicine, University of Ghana Medical School, Korle-Bu, Ghana. ${ }^{6}$ Epidemiology Unit, National Tuberculosis Control Programme, Korle-Bu, Ghana.

\section{Authors' contributions}

KKA was the principal investigator who coordinated the whole survey and also wrote the paper. SVDH contributed to the data analysis, report and the paper writing. GIM was in charge of the field activities, cleaning of the data and paper writing. $\mathrm{AH}$ contributed to the study design, field work and the manuscript editing. CB participated fully in the field work. KAK contributed to the study design. FKA participated in the field activities. FAB contributed to the study design and its implementation. All authors read and approved the manuscript.

\section{Competing interests}

The authors declare that they have no competing interests. 


\section{References}

1. Ghana Statistical Service: 2000 Population and Housing Census, Summary Report of Final Results. Ghana 2002.

2. World Health Organization Report: Global TB Control Report. Geneva, World Health Organization 2006.

3. Ghana Health Service/Ministry of Health: National Tuberculosis Annual Report. Ghana 2001.

4. Wurapa FK, Belcher DW: A tuberculin skin test survey in a rural Ghanaian population. Trop Geogr Med 1976, 28:291-296.

5. Agadzi VK, Pobee JOM, Ikeme AC, Chowdhury GA: Prevalence of tuberculosis in sampled population, Mamprobi, Accra. Ghana Medical Journal 1980, 198-202.

6. World Health Organization: Standard tuberculin test. WHO/TB/Technical Guide. Geneva, Switzerland 1963.

7. Ten Dam HG: Surveillance of tuberculosis means of tuberculin surveys. WHO/TB/85.145. Geneva, Switzerland 1985.

8. Arnadottir Th, Reider HL, Trebucq A, Waaler HT: Guidelines for conducting tuberculin skin test surveys in high prevalence countries. Tubercle and Lung Disease 1996, 77(Suppl):1-20.

9. Eilers PH, Borgdorff MW: Modeling and correction of digit preference in tuberculin surveys. Int J Tuberc Lung Dis 2004, 8:232-9.

10. Rieder HL: Methodological issues in the estimation of the tuberculosis problem from tuberculin surveys. Tuber Lung Dis 1995, 76:114-121.

11. Bosman MC, Swai OB, Kwamanga DO, Agwanda R, Idukitta G, Misljenovic O: National tuberculin survey of Kenya, 1986-1990. Int J Tuberc Lung Dis 1998, 2:272-280.

12. Bleiker MA, Sutherland I, Styblo K, ten Dam HG, Misljenovic O: Guidelines for estimating the risks of tuberculous infection from tuberculin test results in a representative sample of school children. Bull Int Union Tuberc Lung Dis 1989, 64:7-12.

13. Nagelkerke NJD, Borgdorff MW, Kim SJ: Logistic discrimination of mixtures of M. tuberculosis and non-specific tuberculin reactions. Statist Med 2001, 20:111-124.

14. Styblo K: Epidemiology of tuberculosis. Selected papers The Hague, The Netherlands, KNCV 1991, 24.

15. Cochran WG: Sampling techniques. New York, NY: John Wiley \& Sons 1977.

16. Arnadottir Th, Soukaseum H, Vangvichit P, Bounmala S, Vos E: Prevalence and annual risk of tuberculosis infection in Laos. Int I Tuberc Lung Dis 2001, 5:391-399.

17. Egwage $\mathrm{SM}$, Cobelens FG, Muwinge $\mathrm{H}$, Verhage $\mathrm{C}$, Kalisvaart $\mathrm{N}$ Borgdorff MW: The impact of the HIV epidemic on tuberculosis transmission in Tanzania. AIDS 2006, 20:915-21.

18. Nyboe J: The efficacy of the tuberculin test. An analysis based on results from 33 countries. Bull World Health Organization 1960, 22:5-37.

19. Roelsgaard E, Iversen E, Blocher C: Tuberculosis in tropical Africa. Bull World Health Organization 1964, 30:459-518.

20. Van Leth F, Werf van der MJ, Bordorff MW: Prevalence of tuberculous infection and incidence of tuberculosis: a re-assessment of the Styblo rule. Bull World Health Organ 2008, 86:20-6.

Pre-publication history

The pre-publication history for this paper can be accessed here:http://www. biomedcentral.com/1471-2458/10/35/prepub

\section{Submit your next manuscript to BioMed Central and take full advantage of:}

- Convenient online submission

- Thorough peer review

- No space constraints or color figure charges

- Immediate publication on acceptance

- Inclusion in PubMed, CAS, Scopus and Google Scholar

- Research which is freely available for redistribution

Submit your manuscript at www.biomedcentral.com/submit
Biomed Central 